\title{
O verbo, e o voco, no visual: dois exemplos de poesia-zen*
}

Wilberth Clayton Ferreira Salgueiro** I UFES

Resumo: Leitura do poema visual "Zen", publicado no livro Logogramas (1966), de Pedro Xisto, e do videoclipoema "Armazém", lançado no video Nome (1993), de Arnaldo Antunes, a partir, sobretudo, da noção de tempo-e-espaço nas referidas obras e na filosofia zen-budista.

Palavras-chave: poesia-zen, Pedro Xisto, Arnaldo Antunes.

Hoje em dia, quando se diz que "Fulano é zen", subentende-se que o tal fulano é uma pessoa tranqüila, concentrada ou mesmo, até, algo lunática. São noções, note-se desde já, certamente estereotipadas, mas que apontam, metonimicamente, o tipo de entendimento que nossa sensibilidade ocidental dirige à atitude zen-budista, uma "escola" que, da China, passa ao Japão a partir do século XII e aí encontra solo farto para sua expansão.

Um famoso koan zen conta que um discípulo insistia junto ao mestre querendo saber "o que era o zen". Este mestre, em vez das pauladas

* Texto apresentado no evento "Jornada do Poema concreto/processo/ experimental", na Faculdade de Letras da Universidade Federal de Minas Gerais, no dia 22/05/2006, sob a coordenação dos professores Vera Casa Nova e Rogério Barbosa.

**. Prof. Dr. Fac. Letras UFES. 
costumeiras, mantém silêncio. De repente, o obcecado aluno cai, ex machina, num abismo, ficando com os dentes agarrado a um galho apenas. O mestre então lhe pergunta: pode me dizer o que é o zen? ${ }^{1}$ Paradoxo instalado (pois que a resposta conceitual tombará, literalmente, no vazio), percebemos que nossa lógica discursiva e taxonômica entra em colapso diante dessa peculiar maneira zen de dar sentido às coisas pelas coisas mesmas - e não "de fora", "distante" delas. O ascetismo zen quer, em seu ponto ideal, suprimir, ou fundir, sujeito e objeto, crendo numa essencialidade alcançável pelo satori (estado de iluminação intuitiva), e em seu ponto zênite pelo nirvana, quando desejo e consciência individual se extinguem. ${ }^{2}$

Aparentemente, nada mais oposto à filosofia ${ }^{3}$ zen que o rigor cartesiano que impregna a Poesia Concreta brasileira dos anos cinqüenta e, por conseguinte, os herdeiros - produtores de poesia visual - que dela conservam esta austeridade lógica. Todo o lúdico aparato "verbivocovisual" dessas obras persegue incessantemente uma isomorfia construtora, tendo como pilar a geometrização paratática de seus elementos constituintes, isto é, a utilização premeditada do espaço de modo a possibilitar probabilidades combinatórias de coordenação (como no famoso "Tensão", por exemplo, de Augusto de Campos). Esta calculada estrutura concretista parece, em princípio, se contrapor ao modus operandi da maneira zen. Há, porém, muito mais conexões entre poemas visuais e zen-budismo do que imagina nossa muitas vezes não admitida metafísica.

A algumas dessas conexões o poeta "zenmarxistaconcretista" Paulo Leminski, antenadíssimo quanto aos lentos mas inevitáveis vaivéns culturais, refere-se em "Diógenes e o Zen". Para ele, oriente e ocidente se unem no "desabrochar de uma consciência icônica", além da comunicação transverbal. A poesia, em particular, como o zen, seria um "ponto-diamante",

1. Zen-estórias e koans. Tradução: Maria Conceição Couto Netto. Rio de Janeiro: Numen, 1991, p. 71.

2. Cf. SUZUKI, Dasetz Teitaro. Introdução ao Zen Budismo. $2^{\underline{a}}$ ed. Rio de Janeiro: Civilização Brasileira, 1971.

3. Não cabe, aqui, a discussão de ser ou não o zen uma filosofia - e que implicações isso provoca.

4. LEMINSKI, Paulo. Envie meu dicionário: cartas e alguma crítica. Org.: Régis Bonvicino. São Paulo: Editora 34, 1999. Carta 36. 
uma fé includente que "valoriza, absolutamente, a experiência imediata. A intuição. O aqui-e-agora. A superfície das coisas. O instantâneo. O pré ou post-racional".

Se, em suma, de um lado, o zen segue um caminho anticonceitual, para que o pensamento não se fixe num objeto, e o sujeito flua, assim, numa espécie de "grau zen da linguagem" (parodiando Barthes), de outro, a poesia visual precisa se organizar em esquemas rígidos de construção para que o aleatório não se imponha e para que a estrutura ganhe funcionalidade lógica. Ambos, no entanto, concisos e gestálticos, fogem ao paradigma metafísico e buscam num só espaço-tempo o alcance da coisa que, sem dúvida de modo diverso, desejam: que o sujeito seja o ponto de passagem por onde o transverbal icônico se manifeste - no zen, em elementar silêncio; na poesia visual, em imagem-coisa.

Inumeráveis poemas, visuais ou não, já se lançaram à tentativa de criar pontes entre o mundo oriental e o ocidental. Estudos teóricos de múltiplas procedências igualmente pensam esse trânsito intercultural. Octavio Paz, Haroldo de Campos, Roland Barthes e Umberto Eco - todos num campo próximo a uma semiologia antropológica - constituem um respeitável time de teóricos que se interessaram pelo assunto. ${ }^{6}$ Gilles Deleuze, por exemplo, na longa entrevista que concedeu em 1988-1989, surpreende ao - instado a especular a partir da palavra "Ziguezague", iniciada pela última letra do abecedário - trazer para o debate a palavra "Zen", dizendo, em tom jocoso: "O que acontece com o Z? O Zen é o inverso de nez [nariz], que também é um ziguezague. (...) A questão é como relacionar as singularidades díspares ou relacionar os potenciais. (...) Não sei mais em que disciplina científica, mas li um termo de que gostei muito e tirei partido em um livro. Ele explicava que, entre dois potenciais, havia um fenômeno que ele definia pela idéia de um precursor sombrio. O precursor era o que relacionava os potenciais diferentes. E uma vez que o trajeto do precursor sombrio estava feito, os dois potenciais ficavam em estado de reação e, entre os dois, fulgurava o evento visível: o raio!

5. LEMINSKI, Paulo. Anseios crípticos 2. Curitiba: Criar Edições, 2001, p. 114.

6. Conferir: a) BARTHES, Roland. L'empire des signes. Paris: Flammarion, 1970; b) CAMPOS, Haroldo de. A arte no horizonte do provável e outros ensaios. $4^{a}$ ed. São Paulo: Perspectiva, 1977. (Debates, 16); c) ECO, Umberto. Obra aberta. Tradução: Giovanni Cutolo. 9a ed. São Paulo: Perspectiva, 2003; d) PAZ, Octavio. Signos em rotação. Tradução: Sebastião Uchoa Leite. São Paulo: Perspectiva, 1972. 
Havia o precursor sombrio e o raio. Foi assim que nasceu o mundo. Sempre há um precursor sombrio que ninguém vê e o raio que ilumina. O mundo é isso. Ou o pensamento e a filosofia deveriam ser isso. E o grande $Z$ é isso. A sabedoria do Zen também. O sábio é o precursor sombrio e as pauladas - já que o mestre Zen vive dando pauladas - constituem o raio que ilumina as coisas".

Em que pese o sinuoso filosofar do francês, nota-se o destaque que dá ao sino-nipônico hábito "zen", percebendo nele o anagrama nez (nariz), sugerindo sutilmente que a forma curva do olfativo órgão, ziguezagueante portanto, teria similaridade no mínimo gráfica com a palavra "zen", sem adentrar em maiores tergiversações. Doravante, movidos pelo incomum olhar deleuzeano, busquemos, nós outros, elos entre este - enfim - signo cultural "zen" e sua apropriação por parte de dois poetas brasileiros.

O primeiro deles é Pedro Xisto, cujo poema abaixo tornou-se, em meio à produção concretista, um verdadeiro clássico:

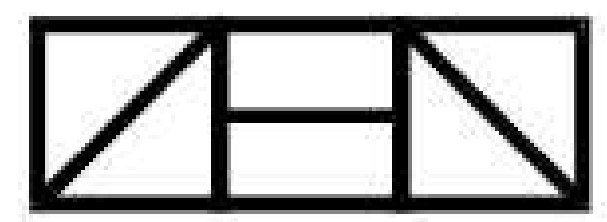

Publicado no livro Logogramas, ' de 1966, "Zen” pertence, portanto, a uma fase posterior ao concretismo inicial (na década de 50, em termos estéticos, imperam ortodoxamente a decretação do fim do verso frásico e a predileção por múltiplos arranjos espaciais). Em termos históricos e culturais, o poema encena precisamente a presença no Brasil, e ademais no mundo, dessa forma mentis oriental. Em Poética e visualidade: uma trajetória da poesia brasileira contemporânea, Philadelpho Menezes inclui esta obra de Xisto no subcapítulo "Poesia semiótica: design de signos ou chaves léxicas?" e sobre ela argumenta: "O casamento perfeito entre o design do signo verbal, sua

7. DeleuZE, Gilles. "O Abecedário de Gilles Deleuze". Referência: http:// geocities.yahoo.com.br/polis_contemp/deleuze_abc.html, em 24/10/2004. [Realização de Pierre-André Boutang, produzido pelas Éditions Montparnasse, Paris. No Brasil, foi divulgado pela TV Escola, Ministério da Educação.]

8. XISTO, Pedro. Logogramas. In: Caminho. Rio de Janeiro: Berlendis e Vertecchia, 1979. 
sintaxe e sua semântica, se dá no poema 'ZEN', do Logogramas de Pedro Xisto, onde a leitura linear da palavra 'zen' é substituída pela visão de conjunto geométrico da forma plástica, nos remetendo à imagem de um templo oriental visto de frente, ou sugerindo, pela conformação rigorosamente simétrica, a estrutura do pensamento oriental desenvolvido sobre a composição dos opostos complementares, a simplicidade na formulação e a própria escrita chinesa, ainda haja parcialmente pictográfica". ${ }^{9}$

Cabe ao leitor, à frente desse poemagem, ver com oswaldianos olhos livres, para, nesse gesto gestáltico, captar na série de traços rigidamente simétricos a combinação de figuras geométricas e, nela, a inscrição - como se num palimpsesto de uma só superfície - da palavra "zen". No grande retângulo que circunscreve o poema, há três quadrados, sendo que o quadrado do meio é composto, por sua vez, por dois retângulos menores; os quadrados laterais se subdividem, cada um deles, em dois triângulos isósceles. A perfeição do equilíbrio e do tamanho das linhas sugere que o poema funciona como uma máquina arquitetural na qual o sujeito se dilui. Dizendo de outro modo, é como se o esforço do sujeito criador quisesse levar a linguagem a um ponto em que ele, sujeito, se subsuma no objeto criado. (Tal atitude, francamente zenista, lembra o célebre lance de Michelangelo, que, quando perguntado como conseguira esculpir tão perfeito "Moisés" do bloco de pedra, teria respondido: "Tudo que fiz foi tirar o excesso".) Refazendo o périplo: mesmo onde não se cria estar - ou seja: numa lógica estritamente matemática -, o "efeito zen" pode surgir, pois como disse Suzuki, "O zen é o ar, o zen é a montanha, o zen é o trovão, o zen é o raio, a flor primaveril, o calor do verão, o frio do inverno; mais do que tudo isso, o zen é o homem".

Para ler e ver a palavra "zen" dentro da escultura gráfica verbivisual que a comporta é necessário um certo desprendimento e uma relativa concentração para decupar o poema, como se composto por fotogramas, "isolando" os traços que compõem as letras "Z", "E" e "N". Gonzalo Aguilar, expert em poemas visuais, confessa a dificuldade que teve para decodificar "Zen": "Devo

9. MENEZES, Philadelpho. Poética e visualidade - uma trajetória da poesia brasileira contemporânea. Campinas, Ed. Unicamp, 1991, p. 80.

10. SUZUKI, Dasetz Teitaro. Introdução ao Zen Budismo. $2^{\underline{a}}$ ed. Rio de Janeiro: Civilização Brasileira, 1971, p. 19. 
reconhecer, ainda correndo o risco de parecer demasiado inepto, que me custou bastante encontrar a palavra 'zen' neste 'texto' de Xisto e que a encontrei quase distraidamente. O esforço em compreender (mal dirigido) só reforçou a minha percepção habitual".

A esse olhar abstrato que, simultaneamente, capta relances do mundo no mundo, olhar que "vê diretamente para dentro das coisas, sem pensar nem refletir", Kenneth David Jackson - num artigo recente em que analisa poemas de Augusto de Campos à luz de efeitos ilusionistas que provocam - nomeou exatamente de "olhar zen". Comentando, a propósito, o poema de Pedro Xisto dirá que, ali, "além do seu equilíbrio e a coincidência entre as letras e a forma geométrica, a imagem é palíndroma, caindo sobre si mesma, como se se anulando; a estrutura reforça e libera a palavra 'ZEN', agora vista como idéia ou conceito e não apenas palavra ou grafia”. ${ }^{12}$ Cabe, ainda, registrar a análise de Marcelo Tápia: "[Vivem] ali, na perfeita simetria do poema, preceitos da filosofia zen, como a harmonia entre opostos, o meio como caminho de equilíbrio, a dialética oriental expressa, explícita na unidade. A leitura igual em espelho ou no verso do papel (mostrando-se a mesma pela transparência) mantém a identidade em verso e reverso, a mesma unidade de opostos complementares, o início-fim de um eterno retorno".

Se, no poema de Pedro Xisto, as figuras geométricas que "escondem" a palavra "zen" - descoberta pelo insight visual que o leitor é levado a experimentar - são o retângulo, o quadrado e o triângulo (logo: linhas retas), no segundo poema em pauta a figura do círculo, sempre em movimento, vai prevalecer. Trata-se do videoclipoema "Armazém", lançado no vídeo Nome (1993), de Arnaldo Antunes:

11. AGUILAR, Gonzalo. Poesia concreta brasileira: as vanguardas na encruzilhada modernista. São Paulo: Edusp, 2005, p. 199.

12. JACKSON, Kenneth David. "Augusto de Campos e o trompe l'oeil da Poesia concreta”. Sobre Augusto de Campos. Org. Flora Süssekind \& Júlio Castañon Guimarães. Rio de Janeiro: 7Letras: FCRB, 2004, p. 30-31.

13. TÁPIA, Marcelo. "Viva Pedro Xisto, visto e revisto". Medusa - revista de poesia e arte. Curitiba, fev.-mar. de 2000, n. 9, p. 10. 


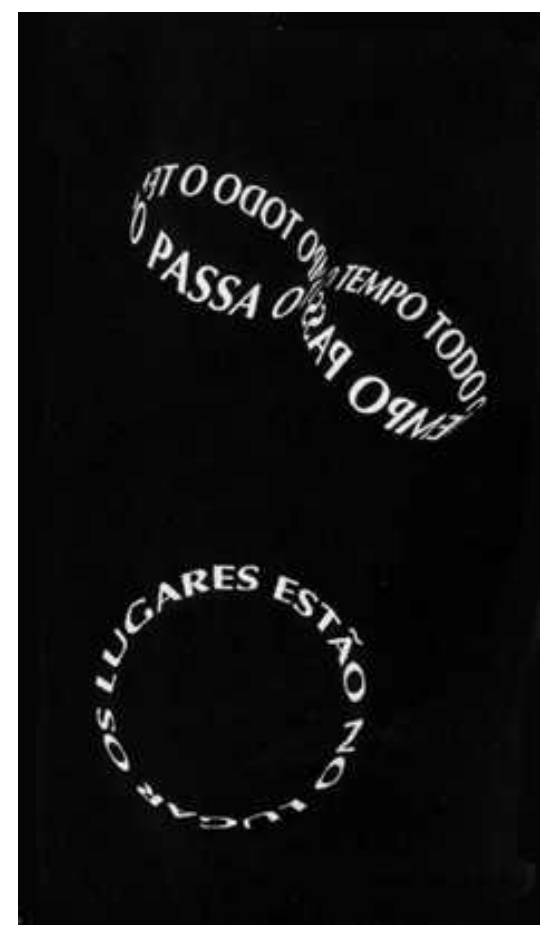

Na verdade, há três versões da obra: a versão gráfica (do livro), a versão sonora (do cd) e a versão clip (do vídeo). ${ }^{14}$ Esta última, sem dúvida, mostra-se a mais completa, pois traz os "versos" do poema em forma de urobórico círculo estampados na tela, movendo-se incessantemente de um lado a outro, enquanto a voz vigorosa do multimidiático poeta, durante 52 segundos, repete - 45 vezes! - variações em torno do vocábulo-título "armazém", gerando "arma zen", "arma sem", "arma cem" e, naturalmente, "armazém". Acompanhado pela guitarra de Arto Lindsay e pela sonoplastia de Peter Price que agrega à voz que recita barulhos de "bambus, pratos e copos", o dístico do livro se transforma na tela em duas esferas verbais que, feito anéis que se entrecruzam, se interpenetram e somem e reaparecem, num movimento constante que segue o ritmo martelado da voz que diz variações da palavra "armazém" enquanto vemos e vamos tentando decodificar na tela

14. ANTUNES, Arnaldo. Nome. Edição da BMG Ariola discos Ltda. Capa, criação e produção gráfica de Arnaldo Antunes, Celia Catunda, Kiko Mistrorigo e Zaba Moreau. São Paulo, 1993. 
o "conteúdo" dos anéis ovalares em andamento, cujo teor heraclitiano, aos poucos, o olhar atento consegue vislumbrar: "o tempo todo o tempo passa /// os lugares estão no lugar", tudo em tipos de cor branca e em caixa alta sobre fundo preto.

Três décadas depois de Pedro Xisto, o intersemiótico poema de Arnaldo Antunes torna a tematizar, esteticamente, a possibilidade da experiência zen na arte ocidental e tecnológica. Mas, é claro, a matéria da história mudou - e com ela as maneiras de expressão. "As formas são sociais", disse Lukács algures. Nos anos 60 espalhou-se pelo mundo, com a força dos ventos contraculturais, e o Brasil não ficou de fora, uma onda de misticismo oriental que, deturpado, deformou-se bastante, servindo, de um lado, a interesses mesmo capitalistas ligados a uma indústria da moda (intelectual, artística, comportamental), e, de outro, a certas tribos que, ainda que procurando genuinamente escapar das garras da referida moda, refugiaramse numa inócua celebração e prática de uma espécie de jubiloso dasein ("estaraí”) zen, sem, no entanto... a cultura zen. Um incontestável testemunho desse período e desse clima temos em Octavio Paz, que, em 1954, já indicava a presença da cultura oriental entre nós, americanos e latinos de todo tipo, destacando sobretudo a estreita aproximação entre haicai e zen-budismo: "Em uma forma voluntariamente anti-heróica a poesia de Bashô nos chama para uma aventura deveras importante: a de nos perdermos no cotidiano para encontrar o maravilhoso. Viagem imóvel, ao fim da qual nos encontramos com nós mesmos: o maravilhoso é nossa verdade humana". ${ }^{15}$ As concepções transcendentalistas do escritor mexicano, se contribuíram para uma clicherização da arte oriental, reduzindo-a à obviedade do diletantismo fácil da "viagem imóvel", no entanto abriram caminho para a crítica da crítica tautológica, anticriativa, perplexa diante de um sapo, de uma poça, de um pulo.

Dentre os métodos zen-budistas para o alcance da iluminação está a repetição - lato sensu - de hábitos, numa disciplina mesmo monástica de que muitos zenistas ocidentais jamais se avizinharam. Esta repetição, bem entendida, tem por base a simplicidade de princípios, em que a "reflexão raciocinante" dá lugar à "percepção instantânea" e em que a "construção simétrica" cede vez à "irregularidade descontínua". O diálogo que "Armazém" de Arnaldo Antunes propõe articular com a filosofia oriental envolve parte destes princípios, sem abandonar a posição - ocidental e contemporânea - de onde se funda expande.

15. PAZ, Octavio. Signos em rotação. Tradução: Sebastião Uchoa Leite. São Paulo: Perspectiva, 1972, p. 166. 
De imediato, seja nas variações oralizadas de "armazém", seja no texto que circula pela tela - "o tempo todo o tempo passa /// os lugares estão no lugar" -, não se detecta nenhuma subjetividade tradicional, que tipifica, por exemplo, a poesia dita expressiva, que "sai" ou se conforma a um "eulírico". Como em "Zen", de Xisto, aqui em Antunes a linguagem em sua performance concretamente verbivocovisual encontra seu apogeu, suspendendo a necessidade de localizar desejos, vontades e intenções autorais. As variações que se armazenam criam pólos, como o yin-yang, antagônicos e complementares em seus possíveis sentidos, produzindo uma mobilização paradoxal característica do zen-budismo: uma "arma", na primeira e hegemônica acepção bélica, jamais seria uma "arma zen", que, contrariamente, quer ignorar as instâncias de dominação e de poder, buscando a harmonia e a paz universal - a "arma zen" seria, assim, uma resposta pacífica aos eternos conflitos sociais e, por que não, individuais; nessa direção, "arma zen" equivale a "arma sem", que, por sua vez, se opõe, sonoramente, ao sentido quantitativo de "arma cem". (Acrescente-se que a história da palavra "armazém" nos diz que seu uso já foi específico como "depósito de armas", depois se ampliando para depósito de utensílios em geral.)

Enquanto somos solicitados pela voz pontual que repete "armazém", o olho acompanha os círculos verbais "o tempo todo o tempo passa" e "os lugares estão no lugar", descobrindo, devagar, que o poema quer-se mesmo redundante, pois, de fato - sem grandes elucubrações metafísicas e sem querer rastrear, em vão, a história filosófica do conceito -, o tempo em sua dimensão cronológica vai passando e a palavra "tempo" também, assim como a palavra "lugar" está em "lugares", dando ao videoclipoema um caráter metalingüístico irreversível. No estado nirvânico, tempo e espaço se elidem, suspendendo-se igualmente a diferença entre sujeito e objeto. Ouvir 45 vezes, em 52 segundos, a "mesma" palavra enquanto o olho acompanha duas esferas em movimento numa tela é, conscientemente, um tipo de representação poética da atitude zen-budista.

Em sua dissertação "Navegar (é) impreciso: reconhecendo a arte do século XX a partir de Nome, de Arnaldo Antunes", Orlando Lopes faz uma reflexão acerca do formato da obra - Nome - em questão que nos interessa de perto: "Escrever é inscrever-se na História da Literatura. Como demonstra o raciocínio zen apresentado por Daisetz Suzuki, todo objeto reporta, em si mesmo, aos outros objetos de mesma classe: a escritura de um poema menciona a existência de 
todos os outros poemas, diria Mallarmé. O artista moderno tem um problema existencial terrível: ele não possui mais uma 'consistência transcendente' (que se materializava na aura problematizada por Walter Benjamin); sua existência é fugaz, e sua produção está fadada a ruir sob o peso da agoridade, a junção de todos os momentos num só momento. O livro - a literatura - é, nesse sentido, uma maneira de ancorar-se num continuum histórico". ${ }^{16}$

Com "Zen" e "Armazém", Pedro Xisto e Arnaldo Antunes depositam seu grão nesse continuum inexaurivel, fluxo que nos faz oscilar entre o fetiche de um mitificado zen - promessa de felicidade e abolição do sofrimento - e o fado de sermos, para o bem e para o mal, demasiadamente ocidentais, ou seja, dependentes logocêntricos. Não podendo ser um (zen), dada a artificiosidade do desejo, nem estando absolutamente presos a dogmas do discurso argumentativo e conceitual, resta-nos, talvez, um lugar outro, entre, indecidível, que é um fingir-se "cá" e "lá". Umberto Eco encerra seu excelente artigo "Zen e Ocidente" exatamente pensando o apelo oriental para nós e aquilo que, aqui, fazemos: “(...) o Ocidente, mesmo quando aceita com alegria o mutável e recusa as leis causais que o imobilizam, não renuncia a redefini-lo através das leis provisórias da probabilidade e da estatística, pois - ainda que nessa nova e plástica acepção - a ordem e a inteligência que 'distingue' são sua vocação". ${ }^{17}$

O "poema-dezenho" de Xisto e o videoclipoema do armazenista Antunes realizam esteticamente essa vocação - de tentar entender o diferente e, mais, dar a ele uma forma artística factível à nossa configuração cultural. Coube a este ensaísta, seguindo as linhas de "Zen" e os sons de "Armazém", desentranhar deles o diálogo com o Budismo Zen ali codificado. Em resumo, do primeiro ("Zen", de Xisto), se fixe a forma nada fortuita com que a palavra "zen" se faz presente na geometria simétrica concretista; do segundo poema ("Armazém", de Arnaldo), fiquem a repetição sonora, hipnotizante, de "armazém", e as palavras "tempo" e "espaço" escapando circulares pela tela, logo, pelos olhos. Em ambas as obras, a lúdica suspensão do sujeito - a imanente plenitude do objeto.

16. ALBERTINO, Orlando Lopes. Navegaré (im)preciso: reconhecendo a arte do século XX a partir de Nome, de Arnaldo Antunes". Ufes. Dissertação, 1999, p. 52.

17. ECO,Umberto. Obra aberta, p. 225. 
Fôramos um John Cage, e toda essa fala se distenderia - performática, filosófica - em silêncio, muda. Mas, recordando Deleuze, o "raio que ilumina as coisas" seduz, mesmo que deixe, por excesso de leis e de luz, bem neblinosa a visão. Ou quase, não?, nos dizem esse dois exemplos visuais de "poiezen".

Abstract: This article is a reading of the visual poem "Zen", published in the book Logogramas (1966), by Pedro Xisto, and of the videoclippoem "Armazen", included in the video production Nome (1993) by Arnaldo Antunes, from the perspective, mostly, of time and space notions to be found in the poems and in Zen-Buddhist philosophy. Key words: Pedro Xisto, Arnaldo Antunes, Zen-Buddhism.

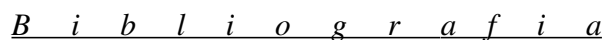

AGUILAR, Gonzalo. Poesia concreta brasileira: as vanguardas na encruzilhada modernista. São Paulo: Edusp, 2005. p. 199.

ALBERTINO, Orlando Lopes. Navegar é (im)preciso: reconbecendo a arte do século XX a partir de Nome, de Arnaldo Antunes. Ufes. Dissertação, 1999.

ANTUNES, Arnaldo. Nome. Edição da BMG Ariola discos Ltda. Capa, criação e produção gráfica de Arnaldo Antunes, Celia Catunda, Kiko Mistrorigo e Zaba Moreau. São Paulo, 1993.

BARTHES, Roland. L'empire des signes. Paris: Flammarion, 1970.

CAMPOS, Haroldo de. A arte no horizonte do provável e outros ensaios. 4. ed. São Paulo: Perspectiva, 1977. (Debates, 16)

DELEUZE, Gilles. "O Abecedário de Gilles Deleuze”. Referência: http:// geocities.yahoo.com.br/polis_contemp/deleuze_abc.html, em 24/10/2004.

ECO, Umberto. Obra aberta. Tradução: Giovanni Cutolo. 9. ed. São Paulo: Perspectiva, 2003.

JACKSON, Kenneth David. Augusto de Campos e o trompe l'oeil da Poesia concreta. In: SÜSSEKIND, Flora; GUIMARÃES, Júlio Castañon (Org.) . Sobre Augusto de Campos. Rio de Janeiro: 7Letras: FCRB, 2004, p. 11-35.

LEMINSKI, Paulo. Diógenes e o Zen. In: Anseios crípticos 2. Curitiba: Criar Edições, 2001. p. 111-115.

LEMINSKI, Paulo. Envie meu dicionário: cartas e alguma crítica. Org.: Régis Bonvicino. São Paulo: Editora 34, 1999. Carta 36.

MENEZES, Philadelpho. Poética e visualidade - uma trajetória da poesia brasileira contemporânea. Campinas, Ed. Unicamp, 1991.

PAZ, Octavio. Signos em rotação. Trad. Sebastião Uchoa Leite. São Paulo: Perspectiva, 1972. 
O eixo e a roda: $v .13,2006$

Disponível em: bttp://www.letras.ufmg.br/poslit

SUZUKI, Dasetz Teitaro. Introdução ao Zen Budismo. 2. ed. Rio de Janeiro: Civilização Brasileira, 1971

TÁPIA, Marcelo. Viva Pedro Xisto, visto e revisto. Medusa - revista de poesia e arte. Curitiba, fev.-mar. de 2000, n. 9.

XISTO, Pedro. Logogramas. In: Caminho. Rio de Janeiro: Berlendis e Vertecchia, 1979.

Zen - estórias e koans. Trad. Maria Conceição Couto Netto. Rio de Janeiro: Numen, 1991. 